\title{
Office Agents: Personal Office Vitality Sensors with Intent
}

\author{
Sjoerd Stamhuis \\ Eindhoven University of Technology, Industrial Design \\ Department \\ s.stamhuis@student.tue.nl \\ Steven Vos \\ Department of Industrial Design, Eindhoven University of \\ Technology, Eindhoven, Netherlands. and School of Sport \\ Studies, Fontys University of Applied Sciences, Eindhoven, \\ Netherlands \\ s.vos@tue.nl
}

\begin{abstract}
In smart office buildings, almost every aspect of the environment can be assessed and adjusted by sensors. Yet employees rarely have access to the data collected to act upon it. It is also unclear what they would find meaningful to follow the recommendations on healthy work conditions and behavior, while productivity is the priority. The Office Agents are a set of artefacts placed on the employee's desk, which capture data about the office environment. Air quality, sound level, light exposure, productivity, and physical activity level are measured to provide office workers with feedback on the 'best' working conditions. Using speculative design and Objects with Intent, the employee engages in a negotiation with the Office Agents based on the office ecosystem. Through this project and interactivity session, we open a debate on the use of sensors in office environments and the stakes around office vitality from the viewpoint of the employees.
\end{abstract}

\section{CCS CONCEPTS}

- Human-centered computing $\rightarrow$ Human computer interaction (HCI); Interaction techniques.

\section{KEYWORDS}

sensors technology, office work, speculative design, sedentary behavior, personal data

\section{ACM Reference Format:}

Sjoerd Stamhuis, Hans Brombacher, Steven Vos, and Carine Lallemand. 2021. Office Agents: Personal Office Vitality Sensors with Intent. In CHI Conference on Human Factors in Computing Systems Extended Abstracts (CHI '21 Extended Abstracts), May 08-13, 2021, Yokohama, Japan. ACM, New York, NY, USA, 5 pages. https://doi.org/10.1145/3411763.3451559

Permission to make digital or hard copies of part or all of this work for personal or classroom use is granted without fee provided that copies are not made or distributed for profit or commercial advantage and that copies bear this notice and the full citation on the first page. Copyrights for third-party components of this work must be honored For all other uses, contact the owner/author(s).

CHI '21 Extended Abstracts, May 08-13, 2021, Yokohama, Japan

(c) 2021 Copyright held by the owner/author(s).

ACM ISBN 978-1-4503-8095-9/21/05.

https://doi.org/10.1145/3411763.3451559

\author{
Hans Brombacher \\ Eindhoven University of Technology, Industrial Design \\ Department \\ j.g.brombacher@tue.nl \\ Carine Lallemand \\ Department of Industrial Design, Eindhoven University of \\ Technology, Eindhoven, Netherlands. and \\ Human-Computer Interaction research group, University \\ of Luxembourg, Esch-sur-Alzette, Luxembourg \\ c.e.lallemand@tue.nl
}

\section{INTRODUCTION}

In recent years, we see a strong trend of smart buildings, using technological solutions such as sensor data to optimize energy efficiency or improve the health, safety and comfort of building occupants through automation. Air conditioning, heating and light conditions are the main parameters sensed as part of environment monitoring processes [13]. Smart office buildings in the near future will likely sense, assess and adjust almost every aspect of the office indoor environment. Sensing technology embedded in the infrastructure is however often purposively "invisible" to the end-users [14], who also do not have access to the data generated or the algorithms used for optimization. Some discussions, mostly at the technical level, arise whether mobile sensors network could compensate the weaknesses of stationary monitoring sensors in buildings [14]. These are described as "low-cost miniatures sensors, carried by individuals" [14]. While the effects of several characteristics of the physical work environment on the users is widely acknowledged, on both the wellbeing and productivity aspects $[1,8,10,11]$, end-users are rarely given access to this data and its meaningfulness for employees is under-researched. Which data from their working environment would office workers like to access and visualize? How would they react to such data to improve their own health or productivity? Do they actually care, or are they happy to leave this responsibility in someone else's hand? Would they be worried about privacy-related concerns if they would understand the extent of data collected?

Additionally, literature presents a myriad of recommendations to improve office workers' health and vitality. Beyond the aforementioned sound, light and heating conditions, sedentary behavior and sitting time $[4,8]$ is also emphasized as a key factor for office vitality, leading to various design interventions both traditional [2, 4-6] and speculative [7, 9]. Yet how can office workers manage to conciliate all these factors, while also maintaining a high productivity? If some aspects are competing or contradicting each other, which one would one prioritize over the others?

In this speculative design project, we use research-throughdesign in order to understand the stakes around office environment optimization from the point of view of the employees, as well as to open a debate around the pervasive use of sensors and data in the workplace. We created a set of office sensors as objects with intent, "computing artefacts designed to have intentions and able 


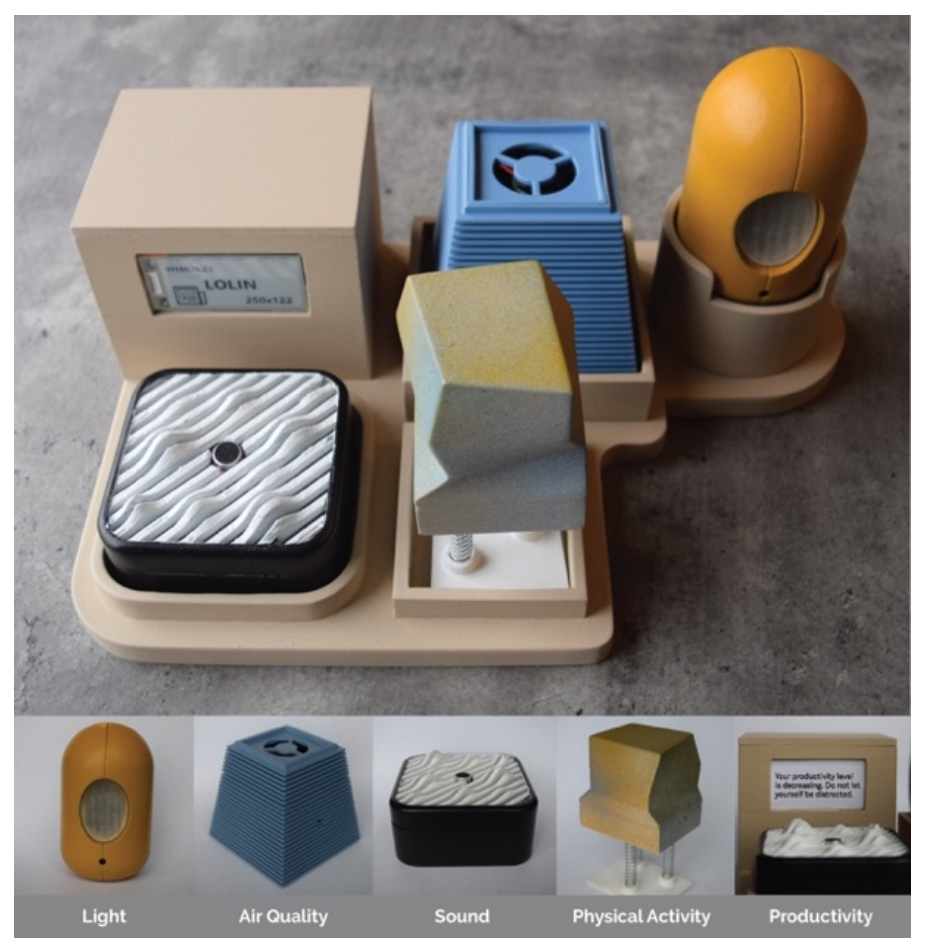

Figure 1: The Office Agents, a set of desk-based artefacts capturing data about the office environment

to express these intentions" [12] supposed to empower office workers to become more vital at work. Through their sometimes bossy personality, the contradicting requests they make and the disruption they might create in the work flow, we collect insights on this timely topic.

\section{OFFICE AGENTS}

The Office Agents are a set of five sensing artefacts placed on the employees' desks, which capture data about the office environment. Air quality, sound level, light exposure, productivity, and physical activity level are measured via sensors to provide office workers with feedback on the healthier working conditions. Each artefact combines sensing capacity with a way of giving feedback to the users when a certain threshold is reached. The shape of objects and feedback mechanisms were designed carefully considering the metaphorical distance with the sensor data they represent. For instance, the Air Quality Agent blows air via a small ventilator to indicate when the surrounding air quality is insufficient. The Sound Agent, inspired by the waves of sound, provides feedback by buzzing whenever the ambient noise level is too high. The Light Agent lights up when light exposure is too low. The Physical Activity Agent is mounted on springs and wiggles when the users have been sitting too long. Finally, the Productivity Agent is embedded in the desk organizer, as it assumes that your work should be done at your desk. It gives textual prompts to keep you focused. While the Office Agents are functional and could act as traditional personal sensors, we designed them following a speculative design approach with the aim to trigger debate and collect insights into the use of sensors data to improve the vitality of office workers.

\subsection{Objects Personas and Actors' Network}

To design the personality of our Office Agents, and give them a form of intent [12], we created five object personas [3] (Figure 2) and represented their interactions or attitudes using an actor network (Figure 3).

\subsection{Technical Specifications}

The Office Agents are individually controlled with Wemos D1 Mini controllers, powered by $800 \mathrm{mAh}$ batteries (Figure 4). The agents are connected to OOSCI (http://oocsi.id.tue.nl), an open-source prototyping middleware platform allowing open connectivity of IoT devices. The OOCSI platform sends the data to Data Foundry, an online platform for design researchers to collect, store, process and export data. This data can be exported or streamed back in realtime into prototypes. All agents (except Productivity) include an accelerometer (MPU6050) to detect if users are moving the agents from their base. The input of the agents is measured via sensors: light (TEMP6000), air quality (CCS811), sound (MAX4466), movement (MPU6050) or software data (productivity via the RescueTime ( $\mathrm{API})$. The output of the designs has been designed based on an action metaphorically similar to the measured data: light (LEDs), air (ventilator), sound (vibration), physical activity (movement) and productivity (text message on an e-ink display). The program developed for the agents measures the input of the sensors and compares this with a predefined threshold. If the data is higher than the given threshold, the output mechanism will be triggered. 
Object persona

Physical activity Agent

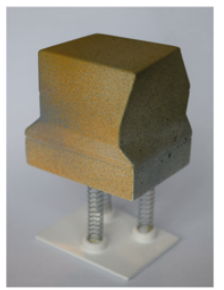

"Sitting is the new smoking! We will fight sedentary behaviour together by making every day at work, an active day at work"

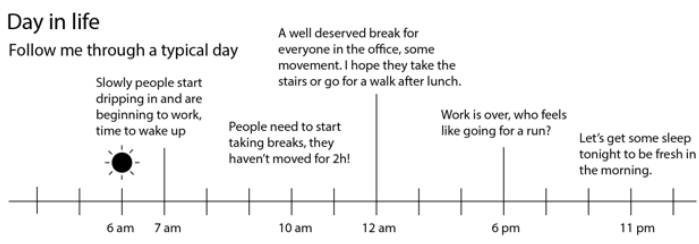

\begin{tabular}{|c|c|c|c|}
\hline Personality & Attitude towards life & Temperament & General mood \\
\hline $\begin{array}{l}\text { Active, playful and } \\
\text { cheerful person }\end{array}$ & $\begin{array}{l}\text { Be active, be healthy, } \\
\text { be happy! }\end{array}$ & Energetic, enthusiastic & Enlightened and joyful \\
\hline Needs & Likes and dislikes & Aspirations & Desires \\
\hline $\begin{array}{l}\text { Movement every } 30 \\
\text { minutes and more } \\
\text { steps every day }\end{array}$ & $\begin{array}{l}\text { Disikes computer and } \\
\text { chairs. Sedentary } \\
\text { behaviors are killing us. } \\
\text { Loves being outside }\end{array}$ & $\begin{array}{l}\text { Promoting the practice of } \\
\text { walking meetings } \\
\text { Elevators are evil, they } \\
\text { should be forbidden }\end{array}$ & $\begin{array}{l}\text { That everyone moves } \\
\text { enough during the day by } \\
\text { finding active ways of } \\
\text { working }\end{array}$ \\
\hline Frustrations & Fears & Complexes & Skills \& Abilities \\
\hline $\begin{array}{l}\text { Emails and notifica- } \\
\text { tions pushing people } \\
\text { to alwayss "finish"a few } \\
\text { more things }\end{array}$ & $\begin{array}{l}\text { People do not take him } \\
\text { seriously or getannoyed } \\
\text { by its enthusiasm to move }\end{array}$ & $\begin{array}{l}\text { Is often disturbing the } \\
\text { other Agents }\end{array}$ & $\begin{array}{l}\text { Attracting people's } \\
\text { attention using my springs } \\
\text { Getting people to move } \\
\text { and clear their mind }\end{array}$ \\
\hline Ambitions & Typical behaviour & Habits & The ideal life would be \\
\hline $\begin{array}{l}\text { Making everyone } \\
\text { healthy }\end{array}$ & $\begin{array}{l}\text { Walking and jumping } \\
\text { around }\end{array}$ & $\begin{array}{l}\text { Trying to get everyone } \\
\text { outside all the time }\end{array}$ & $\begin{array}{l}\text { Making office work a more } \\
\text { active job type }\end{array}$ \\
\hline
\end{tabular}

Social relationships

Allies

$\begin{array}{ll}\text { Air Agent } & \text { Productivity Agent } \\ \text { Light Agent } & \text { Sound Agent }\end{array}$

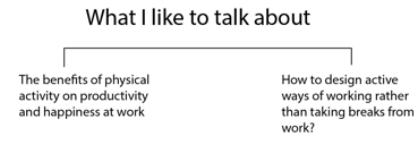

Figure 2: Example of one of the object personas (the physical activity agent)

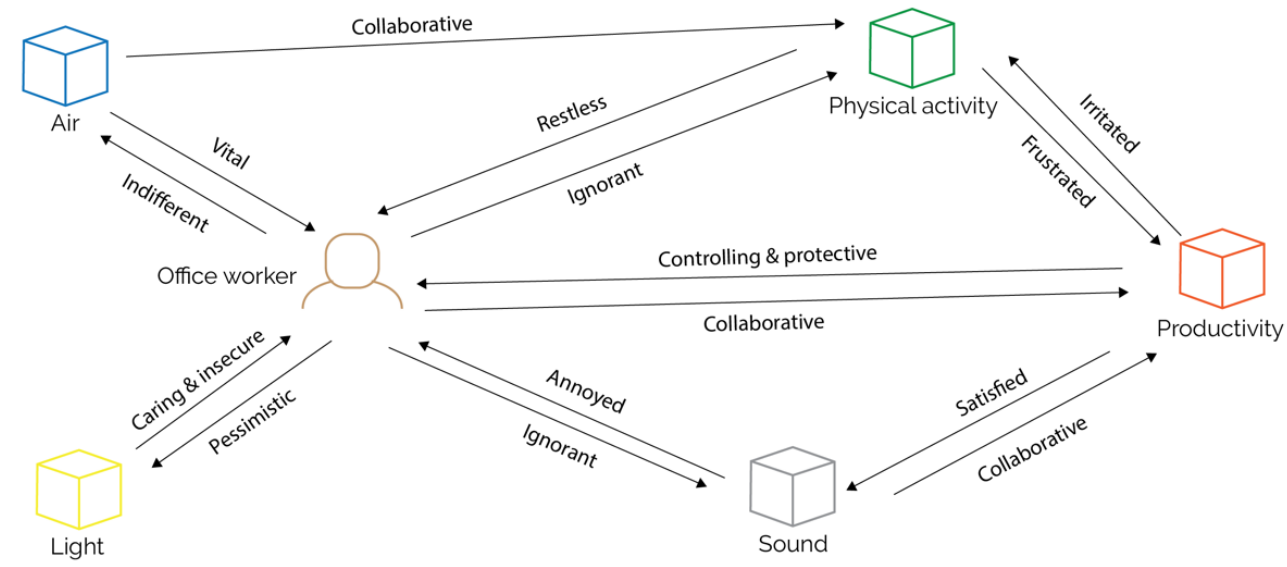

Figure 3: Actor network representing the interactions and interdependencies between the five Office Agents
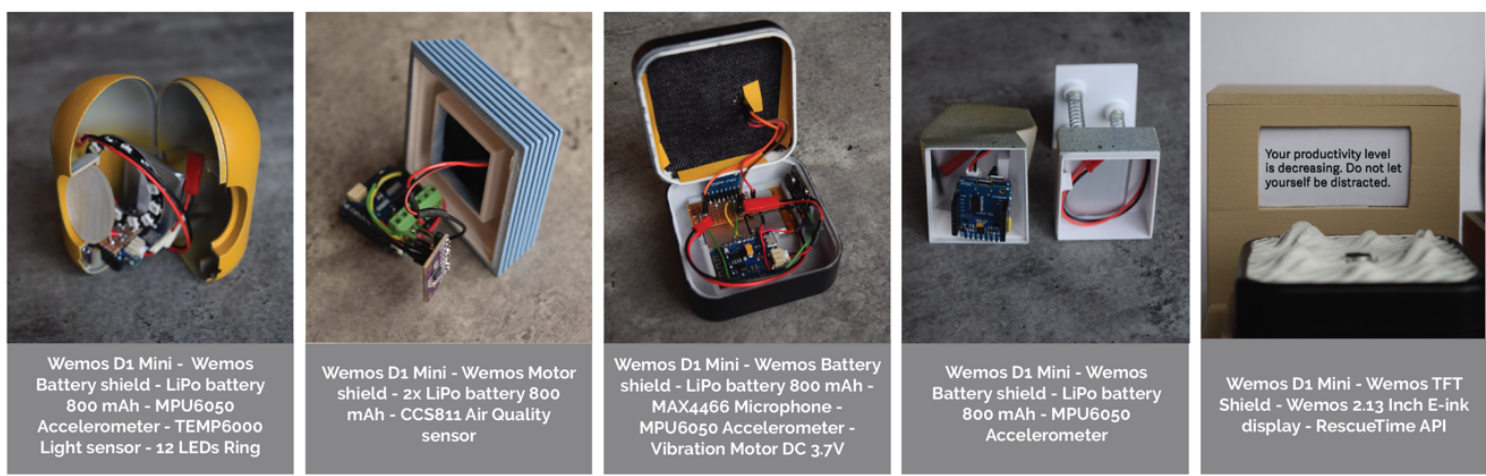

Figure 4: Technical components used for each of the five Office Agents sensing artefacts 


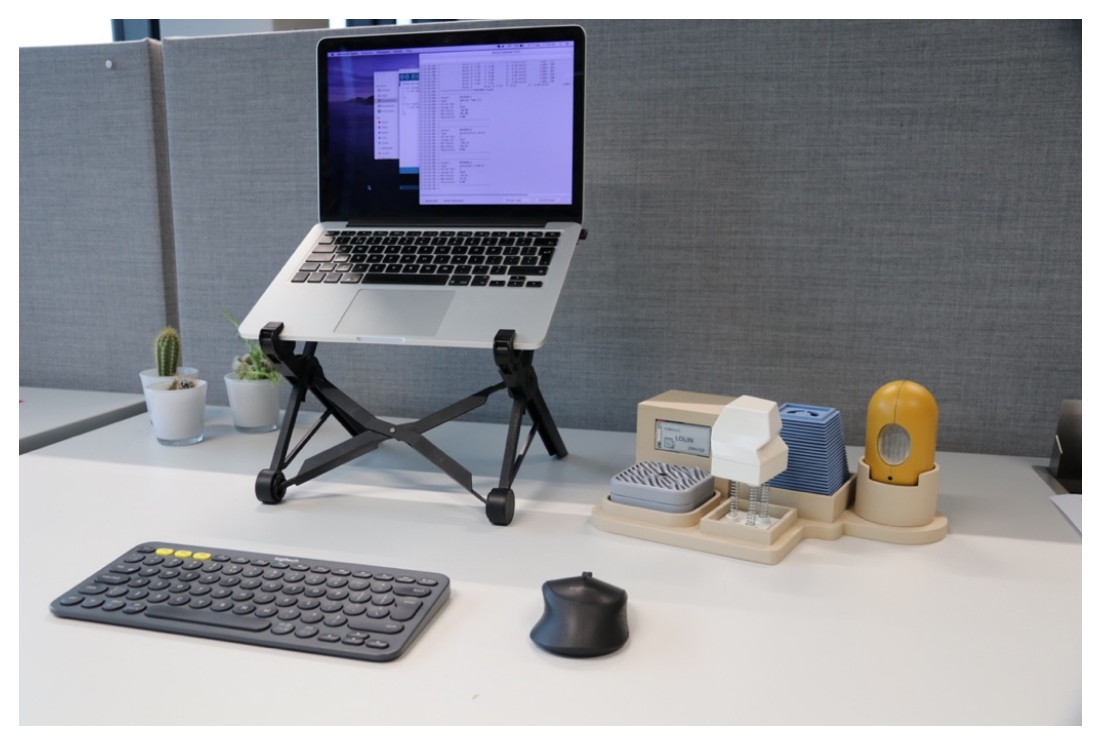

Figure 5: The live demo will showcase an office worker reacting to the requests of the Office Agents, personified by the attendees.

\section{REMOTE LIVE DEMONSTRATION SETUP}

The online demonstration will be organized as an immersive role-play showcasing one office employee working at their desk, equipped with the Office Agents sensor set. When joining the demo session online (using the video conference system chosen by $\mathrm{CHI}$ ), each attendee will be invited to discover the personality of each of the 5 sensing artefacts (based on the object personas and the actor network, Figures 2 and 3) and to select the one they would like to personify. Would you rather be the bossy productivity agent who wants to keep the office worker at their desk at all costs or the physical activity one, who joyfully attempts to promote frequent breaks, standing work or walking meetings? What about the noise agent, for who silence is golden? Or the light and air agents, frequently agreeing on finding a working spot near a window?

The sensor data captured by each of the agents will be displayed live to the audience. Attendees role playing an agent can see the working situation via the webcam, as well as the live sensor data. Sensors already have a defined threshold to actuate, yet this is done in a rather subtle way at the moment. We propose that each attendee can decide when they consider the situation acceptable or not for their Agent and react to this by asking the office worker to adjust their working situation to enhance its healthiness. They can use the chat feature to send requests to the employee, adjusting the tone of the request to the personality of the agent they represent and the context. They can also interact with other attendees (representing other agents) by agreeing or disagreeing with decisions, and trying to push the office employee to comply with their orders. The employee will adjust live to the requests, by for instance taking a short break or moving to another desk with better conditions. They will also sometimes think out loud to represent their inner conflicts, frustrations or satisfaction.

The waiting time during the demo session will mostly consist of people reading and picking their object persona, and discovering its personality and the relation to other objects. The audience can also find it interesting to adopt a position of observer, looking how the office worker reacts to the interactions and bossy requests (sometimes contradictory) of objects given by other attendees. We pilot tested the situation and we expect the situation to be interesting even for passive attendees, hence there is no real group-size issue.

Through this immersive live - almost theatrical - play showcasing a realistic yet speculative office situation, we will embody all the contradictions and challenges that the situation poses. Our employee will attempt to work while trying to fulfil the wishes and intentions of each of the five office agents who, depending on the actor network, will compete or collaborate to make sure the employee's work is as healthy as possible. Imagine that the productivity agent wants you at your desk at all time to get things done, but the physical activity agent does not find these sedentary behaviors healthy at all and thus recommends frequent breaks. The air quality agent tends to agree that fresh air is necessary, although it would prefer you to find a spot near a window to guarantee good air along the day. Yet everybody like these spots! These are always busy and noisy, which is unacceptable for the Sound Agent, determined to protect you from distractions and auditive fatigue. "You see", said the Productivity Agent, "I was right after all. Stay at your desk and don't move from here, it might not be the best air quality or light level, but at least you are working hard and I can keep an eye on you".

The overarching goal of this speculative demonstration is to trigger a debate about the use of personal sensors in office contexts (as compared to sensors used as part of the building infrastructure, for which employees cannot access the data or act upon it) and about the vitality of office workers in general. We envision having a moderator in the chat suggesting debate topics or asking the audience to share their reflections about what is happening. 


\section{ACKNOWLEDGMENTS}

This research is part of the project POWEr FITTing enabled by Eindhoven Engine.

\section{REFERENCES}

[1] Philomena M. Bluyssen, Sabine Janssen, Linde H. van den Brink, and Yvonne de Kluizenaar. 2011. Assessment of wellbeing in an indoor office environment. Building and Environment 46, 12: 2632-2640. https://doi.org/10.1016/j.buildenv. 2011.06.026

[2] Hans Brombacher, Xipei Ren, Steven Vos, and Carine Lallemand. 2020. Visualizing Computer-Based Activity on Ambient Displays to Reduce Sedentary Behavior at Work. In 32nd Australian Conference on Human-Computer Interaction $(\mathrm{OzCH}$ '20). Association for Computing Machinery, New York, NY, USA, 760-764. https: //doi-org/10.1145/3441000.3441022

[3] Nazli Cila, Elisa Giaccardi. Fionn Tynan-O’Mahony, Chris Speed ans Melissa Caldwell. 2015. "Thing-Centred Narratives: A Study of Object Personas." In Seminar 3: Collaborative Formation of Issues Research Network for Design Anthropology, 1-17 Research Network for Design Anthropology: Aarhus.

[4] Ida Damen, Hans Brombacher, Carine Lallemand, Rens Brankaert, Aarnout Brombacher, Pieter van Wesemael, and Steven Vos. 2020. A Scoping Review of Digital Tools to Reduce Sedentary Behavior or Increase Physical Activity in Knowledge Workers. International Journal of Environmental Research and Public Health 17, 2: 499. https://doi.org/10.3390/ijerph17020499

[5] Ida Damen, Lidewij Heerkens, Annabel van den Broek, Kimberly Drabbels, Olga Cherepennikova, Hans Brombacher, and Carine Lallemand. 2020. PositionPeak: Stimulating Position Changes During Meetings. In Extended Abstracts of the 2020 CHI Conference on Human Factors in Computing Systems. https://doi.org/ $10.1145 / 3334480.3383054$

[6] Ida Damen, Anika Kok, Bas Vink, Hans Brombacher, Steven Vos, and Carine Lallemand. 2020. The Hub: Facilitating Walking Meetings through a Network of Interactive Devices. In Companion Publication of the 2020 ACM Designing Interactive Systems Conference (DIS' 20 Companion). Association for Computing Machinery, New York, NY, USA, 19-24. DOI:https://doi-org/10.1145/3393914.
3395876

[7] Ida Damen, Daphne Menheere, Carine Lallemand, and Steven Vos. 2020. Ivy: Reading a Critical Design for Sedentary Behavior in the Office Context. In Companion Publication of the 2020 ACM Designing Interactive Systems Conference (DIS' 20 Companion). Association for Computing Machinery, New York, NY, USA, 7-12. DOI:https://doi-org/10.1145/3393914.3395893

[8] Małgorzata W. Kożusznik, José M. Peiró, Aida Soriano, and Miriam Navarro Escudero. 2017. "Out of Sight, Out of Mind?": The Role of Physical Stressors, Cognitive Appraisal, and Positive Emotions in Employees' Health. Environment and Behavior 50, 1: 86-115. https://doi.org/10.1177/0013916517691323

[9] Ingmar Nieuweboer, Ida Damen, Hans Brombacher, Pierre Lévy, Steven Vos, and Carine Lallemand. 2020. The Office Jungle: A Vision for Wildness to Turn Offices into Jungles. In Companion Publication of the 2020 ACM Designing Interactive Systems Conference (DIS' 20 Companion). Association for Computing Machinery, New York, NY, USA, 341-344. DOI:https://doi-org/10.1145/3393914.3395818

[10] Anna Puig-Ribera, Iván Martínez-Lemos, Maria Giné-Garriga, Ángel Manuel González-Suárez, Judit Bort-Roig, Jesús Fortuño, Laura Muñoz-Ortiz, Jim McKenna, and Nicholas D Gilson. 2015. Self-reported sitting time and physical activity: interactive associations with mental well-being and productivity in office employees. BMC Public Health 15, 1. https://doi.org/10.1186/s12889-015-1447-5

[11] Mahbub Rashid and Craig Zimring. 2008. A Review of the Empirical Literature on the Relationships Between Indoor Environment and Stress in Health Care and Office Settings. Environment and Behavior 40, 2: 151-190. https://doi.org/10. $1177 / 0013916507311550$

[12] Marco C. Rozendaal, Boudewijn Boon, and Victor Kaptelinin. 2019. Objects with Intent: Designing Everyday Things as Collaborative Partners. ACM Trans. Comput.-Hum. Interact. 26, 4, Article 26 (July 2019), 33 pages. DOI: https: //doi.org/10.1145/3325277

[13] Kwok Wai Tham. 2016. Indoor air quality and its effects on humans-A review of challenges and developments in the last 30 years. Energy and Buildings 130: 637-650. https://doi.org/10.1016/j.enbuild.2016.08.071

[14] Yun Xiang, Ricardo Piedrahita, Robert P. Dick, Michael Hannigan, Qin Lv, and Li Shang. 2013. A Hybrid Sensor System for Indoor Air Quality Monitoring. In 2013 IEEE International Conference on Distributed Computing in Sensor Systems. https://doi.org/10.1109/dcoss.2013.48 